\title{
Dinámica y Evolución de las Barreras Medanosas, Provincia de Buenos Aires, Argentina
}

\author{
Federico I. Isla ${ }^{1}$, Luis C. Cortizo ${ }^{2}$ y Horacio A. Turno Orellano ${ }^{2}$ \\ ${ }^{1}$ Universidad Nacional de Mar del Plata-CONICET, Centro de Geología de Costas y del Cuaternario, C.C. 722, 7600 Mar del Plata, Argentina. \\ Tel: 54-0223-4754060fisla@mdp.edu.ar \\ ${ }^{2}$ Comisión de Investigaciones Cientificas, CGCC, Mar del Plata. \\ lcortiz@mdp.edu.ar,hturno@mdp.edu.ar
}

Recebido 26 de abril 2001; revisado 24 de agosto 2001; aceito 15 de outubro 2001

\begin{abstract}
RESUMEN
Las barreras medanosas Oriental y Austral de Buenos Aires se originaron como consecuencia de la fluctuación holocena del nivel del mar que dejó abundante sedimento litoral que migró hacia el interior. De acuerdo a dataciones radiocarbónicas de materiales obtenidos por debajo de los niveles medanosos se reconocen 3 ciclos de generación de médanos costeros. El primero se originó con posterioridad a la colmatación de ambientes estuarinos (estuarios, laguna costeras, lagunas estuarinas, marismas) aproximadamente hace 6000-4000 años AP dependiendo de la disponibilidad de arena y profundidad del ambiente estuarino. El segundo ciclo de formación de médanos costeros corresponde a una regeneración que se dio entre 3500 y 2400 años AP en ambas barreras. El tercer ciclo es más moderno y corresponde a una reactivación que tuvo lugar entre 1600 y 500 años AP. Estos ciclos son aproximadamente coincidentes con otros que tuvieron lugar en el Hemisferio Sur (Sudáfrica, Nueva Zelandia y Australia). Actualmente, la dinámica de la barreras está siendo significativamente alterada localmente con la fijación, forestación, urbanización y drenaje de los médanos que incrementaron los problemas de erosión costera, y de escasez o contaminación de aguas subterráneas.
\end{abstract}

Palabras clave: barreras - médanos - Holoceno - Buenos Aires

\section{RESUMO}

As barreiras de dunas costeiras do sul e do leste da Província de Buenos Aires tem sua origem relacionada à flutuação holocênica do nível do mar, que disponibilizou abundante sedimento e que posteriormente migrou para o interior do continente. A partir de datações radiocarbônicas de amostras obtidas em níveis abaixo das dunas, foram identificados três ciclos de geração de dunas costeiras. O primeiro ciclo ocorreu após a colmatação de ambientes estuarinos (estuários, lagoas costeiras, marismas), entre 6000 e 4000 anos A.P., dependendo da disponibilidade de areia e da profundidade dos estuários. O segundo ciclo de formação de dunas ocorreu entre 3500 e 2400 anos A.P., estando representado nas duas barreiras. O terceiro ciclo, corresponde a um período de reativação das dunas que ocorreu entre 1600 e 500 anos A.P.. Estos ciclos são aproximadamente simultâneos a outros do Hemisfério Sul, identificados na África do Sul, Nova Zelândia e Austrália. Atualmente, a dinâmica de barreiras está sendo significativamente alterada localmente pela fixação, florestamento, urbanização e drenagem das dunas o que tem aumentado os problemas de erosão costeira e de diminuição e poluição das águas subterrâneas.

Palavras chave: barreiras, dunas costeiras, Holoceno, Buenos Aires

\begin{abstract}
The Eastern and Southern barriers of Buenos Aires originated by a sea-level fluctuation that delivered abundant sand that migrated toward the continent. Using radiocarbon dates performed from material collected below the coastal dunes, three cycles can be achieved. The first cycle originated after the infilling of the estuarine environments (estuaries, coastal lagoons, estuarine lagoons, marshes) approximately 6000 - 4000 years BP depending on sand availability and depth of the estuarine environment. The second cycle of dune formation correspond to a rejuvenation that took place between 3500 and 2400 years BP. The third cycle is younger and it is a reactivation of dunes that took place between 1600 and 500 years BP. These cycles were approximately synchronic with others from the Southern Hemisphere (South Africa, New Zealand and Australia). In modern times, the barrier dynamics was siginificantly altered locally with the fixation, forestation, urbanization and drainage of the dunes, increasing the problems of coastal erosion and groundwater over-explotation and pollution.
\end{abstract}

Keywords: Key words: barriers, coastal dunes, Holocene, Buenos Aires 


\section{Introducción}

Las barreras medanosas de Buenos Aires, Oriental y Austral (figura 1), han evolucionado como consecuencia de la fluctuación del nivel del mar a partir del Holoceno medio (Isla, 1989; Isla, 1998). Sin embargo, se originaron bajo diferentes condiciones de disponibilidad de sedimento, relación con las zonas de aporte, régimen de vientos y en diferentes momentos. Los problemas de disponibilidad de arena en las playas han originado propuestas de clasificar las costas de acuerdo a las relaciones sedimentarias entre la playa y el médano litoral (Isla et al., 1996). Sin embargo, no se conoce en detalle los momentos en que se generaron estos médanos litorales. Como estos médanos migran hacia el interior sobre un sustrato vegetado son comunes las formas parabólicas (ver Barreto et al., 1997) y se puede conocer la edad de iniciación de estos ciclos migratorio al datar con el método del radiocarbono los sedimentos con materia orgánica infrayacentes. La orientación de los médanos transversales en algunos casos se corresponden con los vientos dominantes actualmente; en otros sectores parecen indicar regímenes eólicos diferentes a los de hoy en día. Las acumulaciones de materia orgánica (cuando es abundante) en depresiones intermedanosas indican un momento de estabilidad que permitió la generación de suelos locales que fueron posteriormente sepultados por otros médanos.

El presente trabajo ha recopilado información fragmentaria acerca de estas barreras de médanos, y ha aportado nuevos datos acerca de momentos de estabilización de suelos en las barreras medanosas, y de las edades máximas que pueden tener estas formas eólicas. Gran parte de estas evidencias se han descubierto recientemente por la erosión costera incrementada en los últimos 30 años, o por actividades mineras. Debido a que la actividad humana en estas barreras medanosas recién se ha hecho intensa en los últimos 40 años (no han habido asentamientos humanos que expliquen sress antropogénicos durante el Holoceno), gran parte de las variaciones en los regímenes de vientos se asocian a cambios naturales (climáticos). Por estos motivos, la edad de estos ciclos eólicos ha sido comparada con la de otros ciclos del Hemisferio Sur con los cuales podrían estar emparentados climáticamente.

\subsection{Características morfológicas y climáticas de la costa de Buenos Aires}

La Provincia de Buenos Aires posee una extensa planicie costera que se desarrolló por efecto de una fluctuación holocena del nivel del mar que afectó los terrenos de por sí bajos que constituyen la Cuenca del Salado. En la región conocida como Pampa Deprimida se emplazó una barrera de médanos que se super- puso sobre lagunas costeras y marismas de agua dulce. Por otra parte, más al sur, en la Pampa Ondulada, una barrera de médanos similar se adosó y/o superpuso sobre viejos acantilados labrados en sedimentos PlioPleistocenos. Ambas barreras, oriental y austral, poseen diferencias morfológicas (principalmente la pendiente de la planicie costera) y evolutivas que las distinguen (Isla et al., 1996).

Las playas de este sector de Buenos Aires son esencialmente micromareales. El rango de mareas es menor a $2 \mathrm{~m}$ aunque se alcanza esta amplitud al oeste de Necochea. Naturalmente, las playas habrían sido disipativas. Las playas de mayor energía (reflectivas) se concentraban en las estribaciones del Sistema de Tandilia (Mar del Plata) aunque se han extendido al norte y sur por actividades humanas (extracciones de arena, obstrucciones de la deriva litoral, mal manejo de balnearios, alteración de los ciclos naturales). De acuerdo a mediciones recopiladas en distintos sectores de la costa bonaerense, las alturas de ola son de $0,68 \mathrm{~m}$ en Mar de Ajó, 1,15 m en Punta Médanos, 0,89 m en Pinamar, 0,91 m en Mar del Plata y 1,33 m en Puerto Quequén; los períodos varían entre 7 y 10 segundos (Lanfredi et al., 1992). Los valores más bajos de Mar de Ajó y Pinamar fueron estimados visualmente desde la playa (valores de la última rompiente) mientras que los de Punta Médanos, Mar del Plata y Quequén fueron tomados en la plataforma continental con sensores de presión o acelerómetros.

De acuerdo a las rosas de vientos, la Barrera Austral está dominada por vientos del oeste y ONO que, debido a la orientación oeste-este de esta barrera, favorece la formación de médanos transversales (figura 1). La Barrera Oriental, no tiene una tendencia tan dominante (abundantes los del norte y los del sur) y sólo en algunos sectores (Mar Chiquita - Villa Gesell) se da la abundancia relativa de arena para que se formen médanos transversales. Esta bipolaridad en la frecuencia de los vientos (figura 1) origina la conformación estacional de médanos transversales de cresta invertida.

\section{Métodos}

Con el objeto de analizar las características granulométricas de los médanos litorales y su relación con las playas de aportes y energía de los vientos, se muestrearon los sedimentos superficiales de los médanos transversales en diferentes sectores, al tiempo que se relevaban sus perfiles topográficos. Por otro lado, se describieron, muestrearon y dataron los sedimentos inmediatamente por debajo de los médanos. El propósito fue analizar la edad máxima datable de los sedimentos (conchillas en posición de vida, turba, paleosuelos de depresiones intermedanosas) que fueron sepultados por el movimiento de médanos litorales. Las dataciones fueron realizadas en el laboratorio del 
Museo de La Plata (LATYR) y no tuvieron corrección a calendario sideral o por efecto reservorio. Todas las localidades fueron posicionadas con GPS Trimble Ensign XL.

En laboratorio, los sedimentos fueron secados y tamizados a intervalos de 0,5 unidades fi. Con los pesos obtenidos en cada tamiz se construyeron curvas probabilísticas de las que se obtuvieron los parámetros estadísticos del modo sugerido por Folk y Ward (1957).

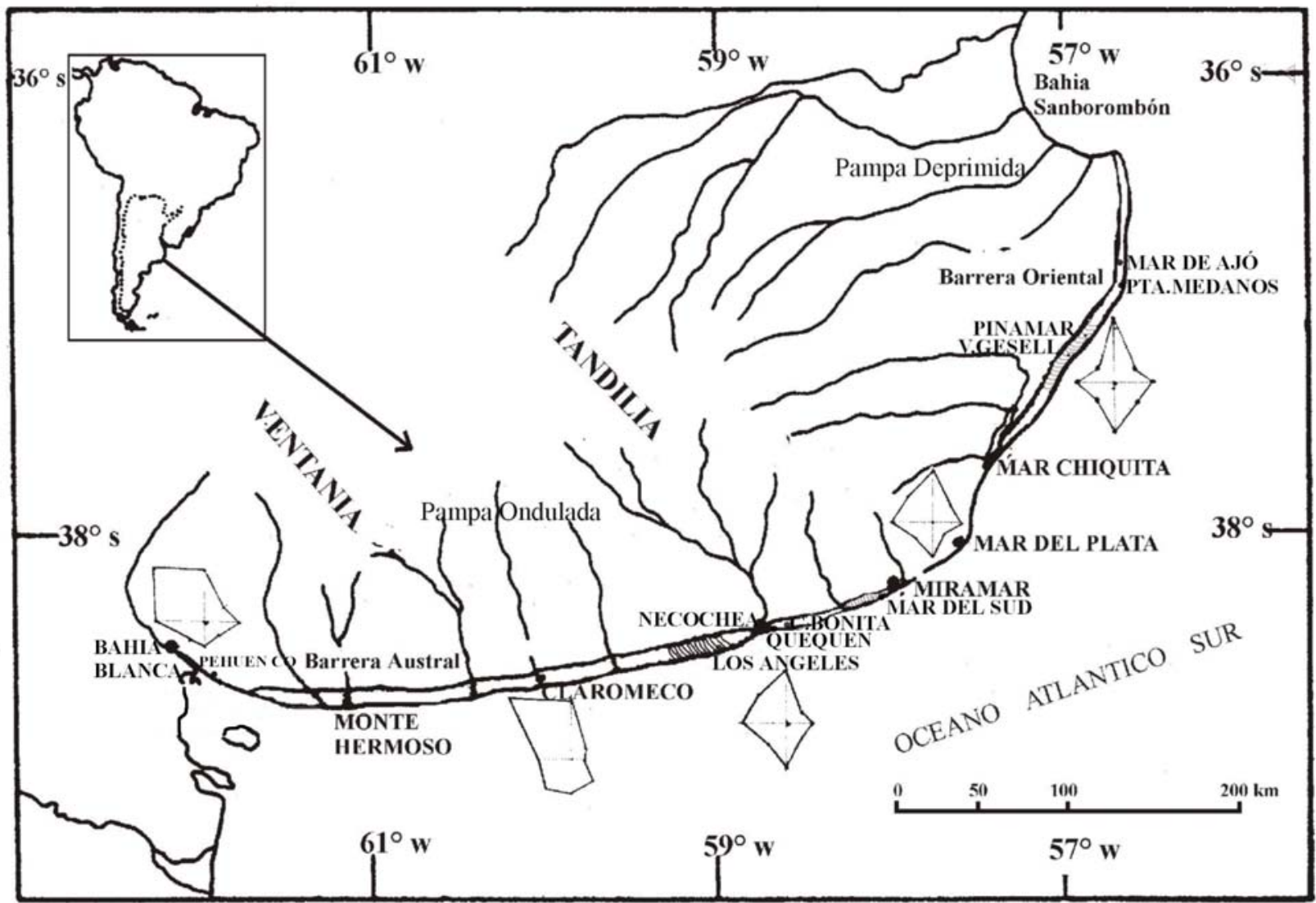

Figura 1. Ubicación de las barreras Oriental y Austral de Buenos Aires en relación a la fluctuación del nivel del mar (modificado de Isla et al., 1996). Las rosas de vientos evidencian que hacia el oeste los vientos de ese cuadrante son más frecuentes.

\section{Resultados}

\subsection{Barrera Oriental de Buenos Aires.}

Según trabajos geológicos llevados a cabo en la zona la barrera medanosa creció desde el NNE hacia el SSO (Schnack et al., 1982) a partir de un paleocabo situado aproximadamente en lo que hoy es Villa Gesell (Violante, 1992). A partir de ese paleocabo Villa Gesell la barrera creció hacia el norte del mismo modo que lo hace actualmente.

Los médanos transversales de la Barrera Oriental fueron reconocidos en el sector entre la Estancia Mar Chiquita y Faro Querandí (figura 2; tabla 1). Se ha reconocido la transición entre parabólicos a barjanoides (figura 3); más hacia el norte toman formas de médanos en estrella (Isla, 1997). Son médanos de arenas medias; gruesas en los sectores de "blowouts" (deflación de finos) y finas en las depresiones intermedanosas (la vegetación captura el material transportado por deflación). De acuerdo a fotografías aéreas entre 1975 y 1987, la migración de estas dunas ha sido mínima (Isla, 1987), y su transporte habría sido originado por vientos del SSO.

De acuerdo a dataciones radiocarbónicas, en esta barrera los médanos sepultaron las turbas que se desarrollaban sobre lagunas costera hace unos 1400 años AP (Tabla 2). La datación de 540 años obtenida en las proximidades de la laguna Mar Chiquita seguramente obedece a muy recientes reactivaciones en la zona costera próxima a la boca de la albufera. Estos médanos litorales muy modernos fueron reconocidos entre la Estancia Mar Chiquita y el Faro Querandí a través de sus disposiciones intermedias entre depósitos de sobrelavados operativos y no operativos (Isla, 1997). 
Isla, F. I. et al. / Revista Brasileira de Geomorfologia, volume 2, nº 1 (2001) 73-83

Figura 2. A) Campo de médanos transversales al sur de la Estancia Mar Chiquita (modificado de Isla, 1997). B) Campo de médanos barjanoides entre la Estancia Mar Chiquita y el Faro Querandí. C) Campo de médanos transversales en la zona de Médano Blanco (Balneario Los Angeles). 
Isla, F. I. et al. / Revista Brasileira de Geomorfologia, volume 2, nº 1 (2001) 73-83

Tabla 1. Datos morfológicos y sedimentológicos de los campos de médanos transversales de las barreras oriental y austral. (Mz: media aritmética. S: desvío estándar)

\begin{tabular}{c|c|c|c}
\hline & $\begin{array}{c}\text { Mar Chiquita } \\
\text { barjanoides }\end{array}$ & $\begin{array}{c}\text { Mar Chiquita } \\
\text { Transversales }\end{array}$ & $\begin{array}{c}\text { Médano Blanco } \\
\text { Transversales }\end{array}$ \\
\hline Orientación & $\mathrm{N} 190$ & $\mathrm{~N} 190$ & $\mathrm{~N} 270$ \\
Espaciamiento (m) & 8,7 & 300 & 400 \\
Altura (m) & & 6,9 & 5,5 \\
Largo (m) & 7,11 & 5 & 11 \\
Pendiente balovento (\%) & 19,5 & 6,8 & 20 \\
Pend. Sotavento (\%) & 1,57 & 0,77 & 1,86 \\
Mz barlovento (phi) & 0,78 & 0,65 & 0,67 \\
S barlovento & 1,93 & 1,16 & 1,26 \\
Mz sotavento (phi) & 0,54 & 0,53 & 1,05 \\
S sotavento & & & 0,93 \\
Mz cresta (phi) & & Arena gruesa-media & Arena media \\
S cresta & Arena media &
\end{tabular}

Tabla 2. Dataciones radiocarbónicas realizadas en la base de médanos de barrera (edades máximas).

\begin{tabular}{c|c|c|c|c|c|c}
\hline Lugar & Latitud & longitud & Edad & \# lab & material & yacencia \\
\hline Faro Querandí & $37^{0} 33^{\prime} \mathrm{S}$ & $57^{0} 11^{\prime} \mathrm{W}$ & $3070 \pm 40$ & $\mathrm{LP}-1066$ & m.o. & dep. intermédano \\
Ea. Mar Chiquita & $37^{0} 37,5^{\prime} \mathrm{S}$ & $57^{0} 16,5^{\prime} \mathrm{W}$ & $1400 \pm 60$ & $\mathrm{LP}-961$ & peat & tope estuario \\
CELPA Norte & $37^{0} 42,5^{\prime} \mathrm{S}$ & $57^{0} 23^{\prime} \mathrm{W}$ & $2750 \pm 70$ & $\mathrm{LP}-723$ & M. platensis & tope estuario \\
CELPA & $37^{0} 45^{\prime} \mathrm{S}$ & $57^{0} 25^{\prime} \mathrm{W}$ & $540 \pm 100$ & Ac-342 & peat & tope estuario \\
Ao. Los Cueros & $37^{0} 47^{\prime} \mathrm{S}$ & $57^{0} 27,3^{\prime} \mathrm{W}$ & $1340 \pm 50$ & Ac-100 & T. plebeius & tope estuario \\
Ao. Las & $38^{0} 14,4^{\prime} \mathrm{S}$ & $57^{0} 47,4^{\prime} \mathrm{W}$ & $2380 \pm 95$ & WP-124 & Ostrea sp & tope estuario \\
Brusquitas & & & & & & \\
El Durazno & $38^{0} 16^{\prime} \mathrm{S}$ & $57^{0} 49,5^{\prime} \mathrm{W}$ & $4310 \pm 40$ & LP-1041 & T. plebeius & tope estuario \\
Punta Hermengo & $38^{0} 17^{\prime} \mathrm{S}$ & $57^{0} 50^{\prime} \mathrm{W}$ & $2690 \pm 60$ & LP-1115 & peat & tope estuario \\
Ao. La Ballenera & $38^{0} 19,5^{\prime} \mathrm{S}$ & $57^{0} 56,5^{\prime} \mathrm{W}$ & $4120 \pm 60$ & LP-743 & Heleobia sp & tope estuario \\
arenera San José & $38^{0} 19^{\prime} \mathrm{S}$ & $57^{0} 55,5^{\prime} \mathrm{W}$ & $3540 \pm 60$ & LP-902 & m.o. & dep. intermédano \\
Río Quequén & $38^{0} 32^{\prime} \mathrm{S}$ & $58^{0} 44,3^{\prime} \mathrm{W}$ & $5740 \pm 110$ & LP-1048 & T. plebeius & tope estuario \\
Punta Negra & $38^{0} 36^{\prime} \mathrm{S}$ & $58^{0} 39^{\prime} \mathrm{S}$ & $1640 \pm 60$ & $\mathrm{LP}-1220$ & m.o. & dep. intermédano \\
Claromecó & $38^{0} 51^{\prime} \mathrm{S}$ & $60^{0} 05^{\prime} \mathrm{W}$ & $840 \pm 70$ & LP-833 & m.o. & dep. intermédano \\
\hline
\end{tabular}

\subsection{Barrera Austral de Buenos Aires}

En Costa Bonita se ha constatado la presencia de playas hace 6000 años (Isla et al., 1996) que habrían permitido la formación de dunas litorales desde esa edad. Los médanos transversales son bastante comunes en la barrera extendida entre Miramar y Pehuén Co. Se los ha reconocido en el sector entre Miramar y Mar del Sur (arroyo La Ballenera; figura 4), y al oeste de Necochea (Médano Blanco, cercano a Balneario Los Angeles; figura 5). En esta porción de costa, la barrera de médanos está compuesta de arena fina (tabla 1) y se depositó con posterioridad a los horizontes con materia orgánica que culminan las secuencias estuáricas. Estos niveles con materia orgánica son muy buenos indicadores de edad ya que no tendrían efectos reservorio significativos. De este a oeste, la secuencia del arroyo
Las Brusquitas culminó hace $2380 \pm 95$ años (tabla 2), la de El Durazno hace $4310 \pm 40$ años, la de Punta Hermengo hace $2690 \pm 60$ años (Figini et al., 1999), la del arroyo La Ballenera hace $4120 \pm 60$ años, y la del Quequén Grande hace $5740 \pm 110$ años. Se desprende de estas edades que algunas secuencias estuáricas fueron colmatadas rápidamente mientras otras menos vinculadas con los aportes de arena fueron cubiertas por médanos en tiempos más recientes. En el campo de médanos transversales que se extienden entre Mar del Sur y Miramar, los médanos de arena media (Media aritmética $=1,6$ unidades phi) moderadamente seleccionada han sido explotados por la Arenera San José. En la base del sector en explotación se descubrió un nivel de materia orgánica (paleosuelo) que dio una edad de $3540 \pm 60$ años AP (tabla 2). 


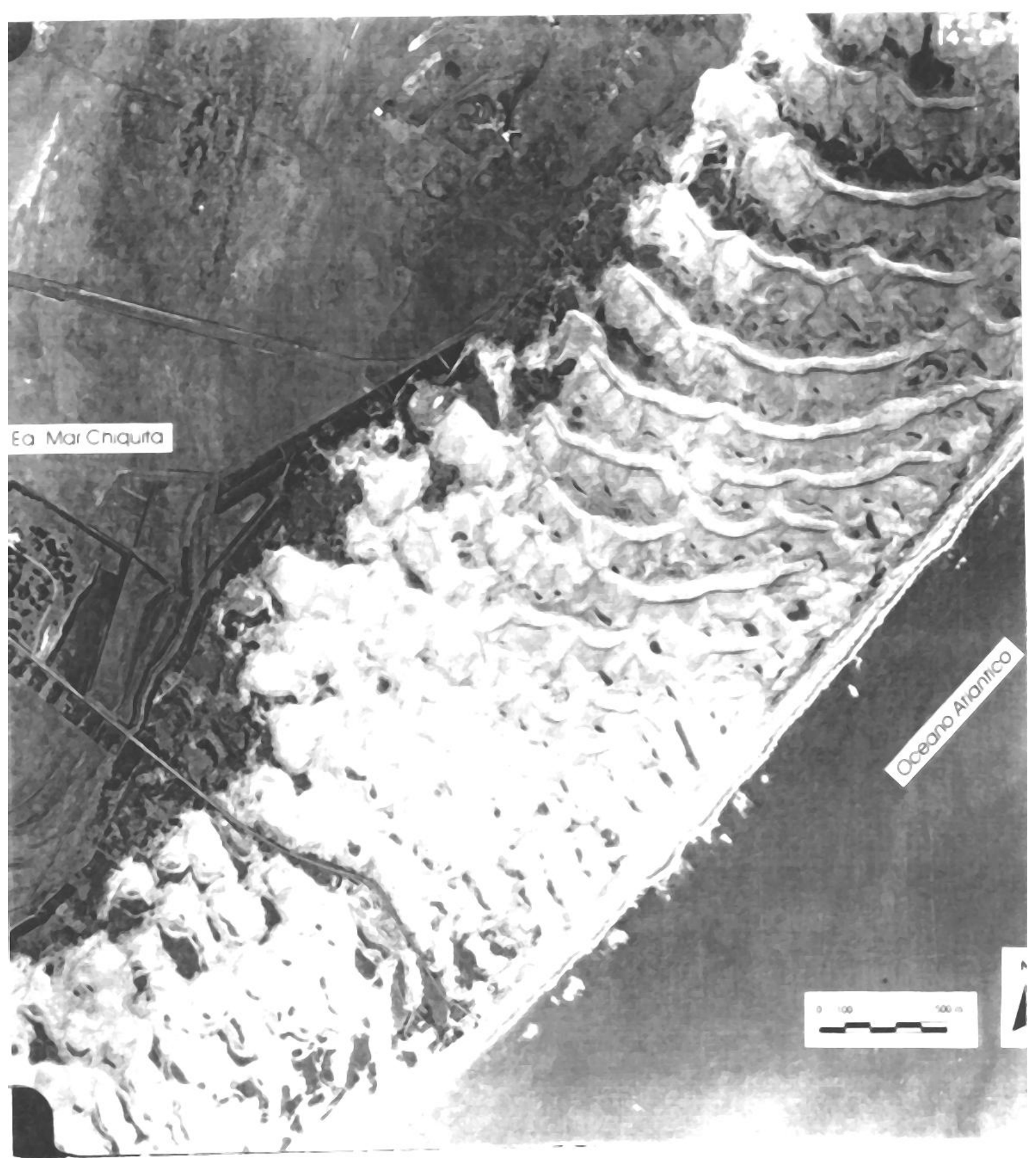

Figura 3. Campo de médanos transversales entre Mar Chiquita y Faro Querandí.

En el campo de médanos transversales que va desde Balneario Los Angeles hasta Punta Negra, se efectuó una datación de materia orgánica intercalada entre depósitos eólicos (futuro Parque eólico Necochea) dio una edad de 1640 160 años AP (tabla $2)$. Actualmente estos médanos transversales constituyen un problema hidráulico desde el momento que obstruyen las desembocaduras y originan inundaciones aguas arriba (figura 5).

La depresión intermedanosa datada en una curva del arroyo Claromecó próximo a la desembocadura no está vinculada a la oscilación del nivel del mar y habría sido colmatada hace $840 \pm 70$ años AP (Stutz, 2000). 


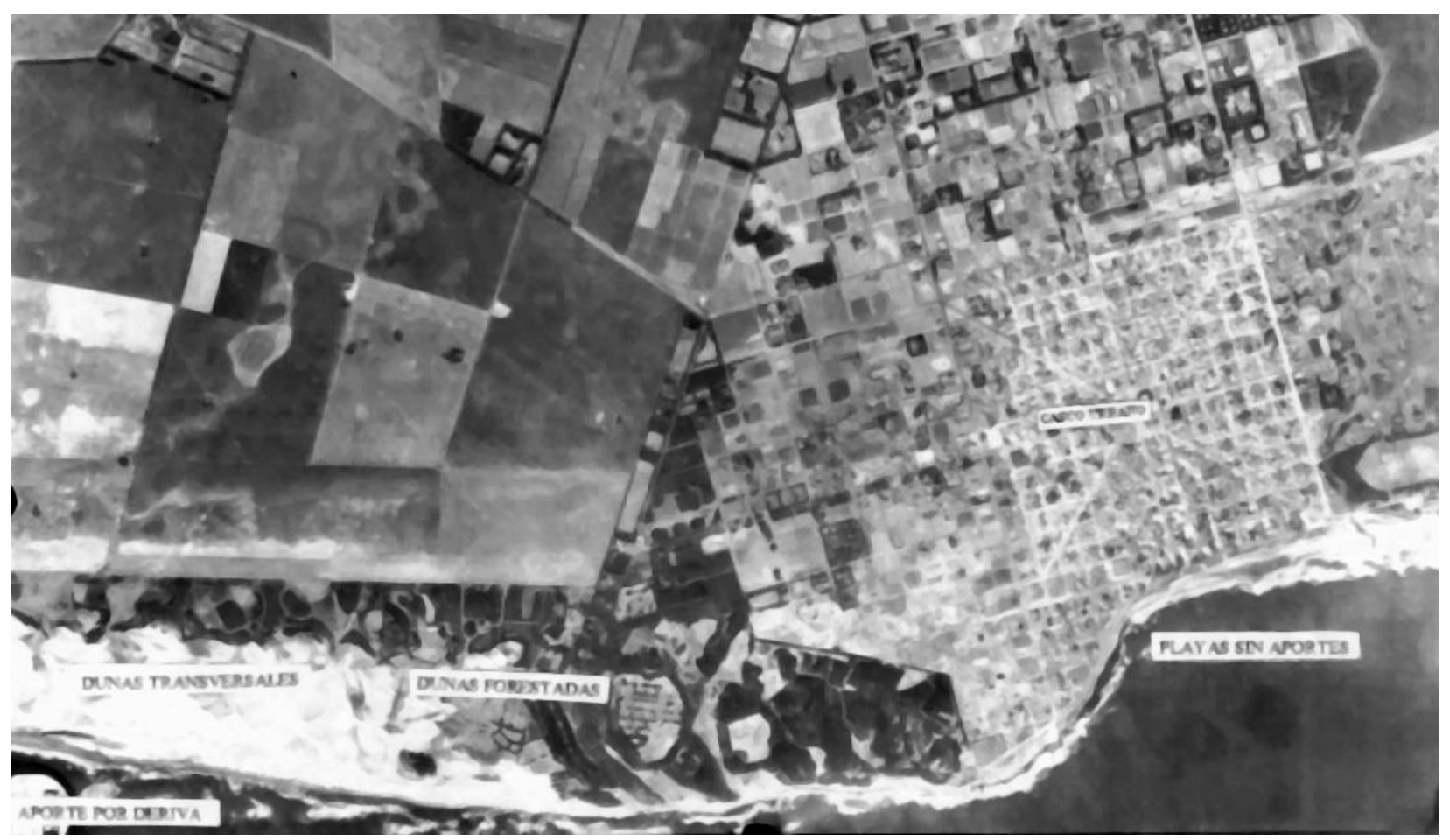

Figura 4. Campo de médanos transversales al oeste Miramar.

\subsection{Análisis de las edades}

A lo largo de la costa de ambas barreras se puede reconocer que la barrera oriental se hace más angosta hacia el sur, en el sentido de la antigua deriva litoral, desapareciendo en Mar del Plata (Schnack et al., 1982; Violante, 1992), y que la barrera austral se hace más angosta hacia el este (figura. 6). Los sedimentos estuáricos que infrayacen la primera generación de médanos (6000 a 4000 años AP) se ubican en una cota inferior. Posteriormente se originó una segunda generación de médanos que sepultó depresiones intermedanosas formadas entre $3500 \mathrm{y}$ 3000 años AP. La tercera generación de médanos costeros es más moderna (1600-500 años AP), representa removilizaciones de arena que sepultaron marismas próximas a la costa (CELPA, Estancia Mar Chiquita) y depresiones intermedanosas que están más desvinculadas de la costa y por lo tanto en una cota más alta (Punta Negra, Claromecó; figura 7).

\section{Discusión}

En la costa sur del Golfo San José (Chubut), en el sitio denominado Garganta del Delfín, se obtuvieron tres edades radiocarbónicas $(2640 \pm 70$, $3220 \pm 70$ y $2450 \pm 60$ años AP) en un sitio arqueológico por debajo de dunas holocenas (Gómez Otero, 1994; Isla et al., 2000). Estas edades demuestran que los médanos longitudinales se movieron con posterio- ridad (2450 años AP) al momento en que los humanos estuvieron asentados en ese sector de costa y durante la regresión del Holoceno.

Comparando la evolución de las barreras litorales de Mar Chiquita (Buenos Aires) y Lagoa dos Patos (RS, Brazil), se constató que se bien han evolucionado bajo tendencias diferentes (vientos del SSW en Mar Chiquita, y del NNE en Río Grande do Sul), ambas barreras están bajo un intenso proceso de erosión costera de depósitos de lagunas costeras y turbas vinculadas a la oscilación holocena del nivel del mar (Isla y Tomazelli, 1999).

En el este de la Provincia del Cabo, Sudáfrica, se detectaron 3 pulsos de formación de dunas costeras: el primero se inició hace aproximadamente 6.500 años AP cuando el nivel del mar alcanzó el nivel actual. El segundo pulso se inició con posterioridad a los 3500 años AP, y el tercero hace unos 1000 años (Illenberger y Verhagen, 1990). Esta cronología se corresponde con los procesos que tuvieron lugar en la costa de la Provincia de Buenos Aires.

En el sudeste de Australia, las dunas costeras indican 3 estadíos de evolución: 1) pre-Holoceno, 2) Holoceno temprano y 3 ) Holoceno medio a tardío (Pye y Bowman, 1984). Los dos primeros estadíos estarían favorecidos por la situación de New South Wales como receptor de los vientos "westerlies" que recorren el desierto australiano. Los campos de dunas costeras se habrían originado por vientos provenientes del S y SE, y las arenas aportadas directamente desde grandes bahías (Pye y Bowman, 1984). 


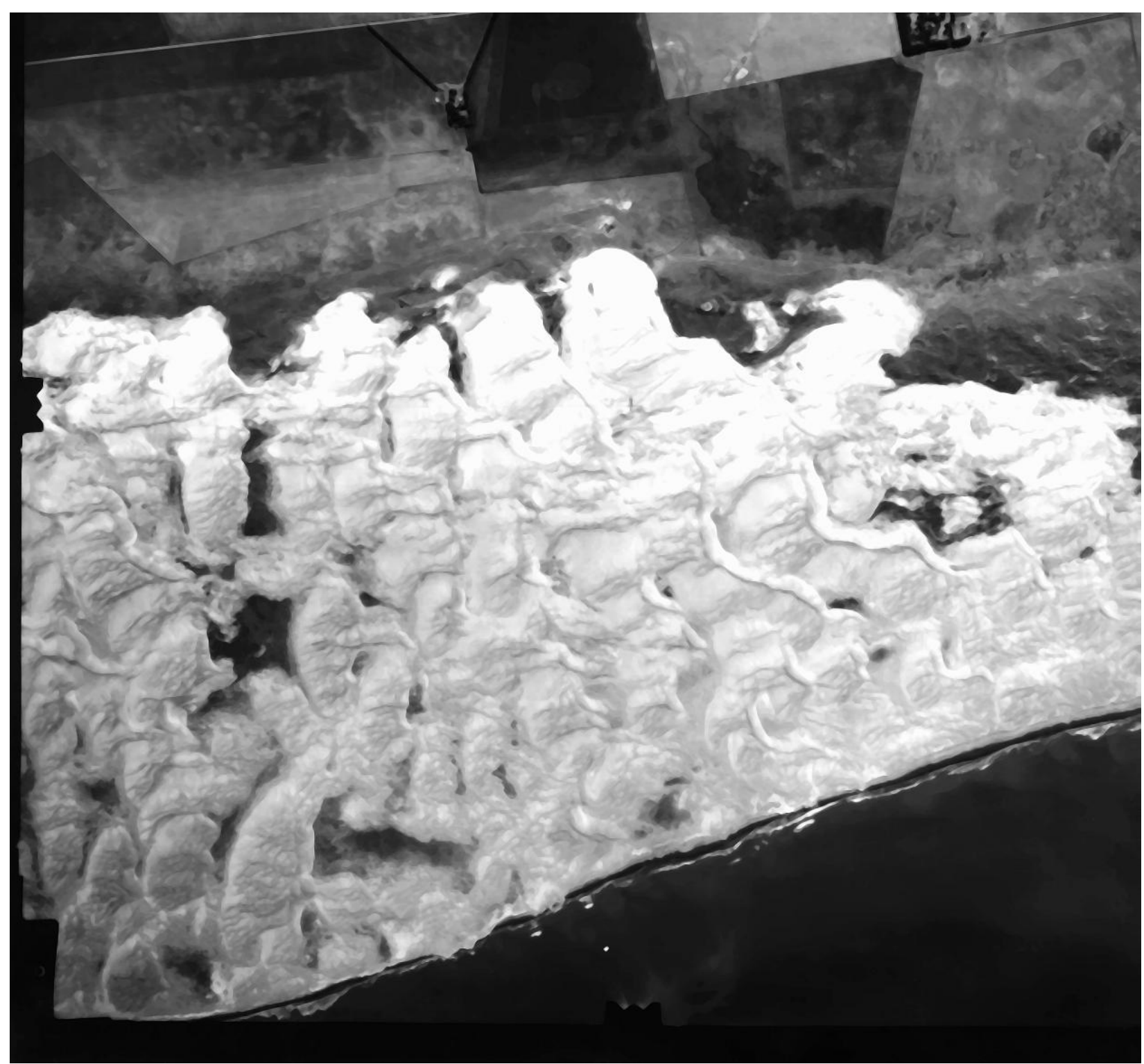

Figura. 5. Campo de médanos transversales que se transportaron en sentido OSO-ENE en el sector de Médano Blanco (Balneario Los Angeles, O de Necochea).

En la costa de Nueva Zelandia, en North Canterbury (cercano a Christchurch), se determinaron varios estadíos de generación de dunas costeras, hace 6500 años, menos de 6000, menos de 2600, 1000 y 500 años (Shulmeister y Kirk, 1996). En las cercanías de Manawatu, se han reconocido cuatro ciclos que se habrían iniciado hace 6500 años $\mathrm{AP}($ fase 1$)$, hace 3500 años AP (fase 2), la tercer fae estaría relacionada con la ocupación maorí (fase 3, 1000 años AP) y la última estaría relacionada a la ocupación europea (Muckersie y Shepherd, 1995).

La primera generación de dunas costeras hace 6500-6000 años resulta ser aproximadamente coincidente en las mismas latitudes del Hemisferio Sur (Buenos Aires, Sudáfrica, New South Wales y Nueva Zelandia) y está condicionada con el nivel del mar aproximadamente semejante al actual alcanzado en esa época en todo el Hemisferio Sur (ver Isla, 1989).

En la costa noroeste del Oceáno Pacífico, en las Islas Bering, Kunashiri e Iturup, se registraron tres estadíos de generación de dunas costeras durante el Holoceno. El primero, Límite Atlántico-Sub boreal, corresponde con la regresión del Holoceno Medio que produjo un descenso relativo de $4 \mathrm{~m}$ en el nivel del mar. El segundo, Subatlántico, corresponde a edades radiocarbónicas entre 2350 y 1300 años AP. El tercero se asigna a la Pequeña Edad de Hielo, con edades aproximadas a 500 años radiocarbónicos AP (Razigaeva et al., 1996).

Los resultados enumerados se han limitado a describir (morfología y edad) los ciclos naturales de generación o reactivación de médanos costeros. En tiempos recientes estos médanos han sufrido una 
intensa alteración por actividades humanas vinculadas al turismo costero. En primer término existe un intenso proceso de fijación y forestación de médanos (Isla et al., 1998; Turno Orellano e Isla, 1999).

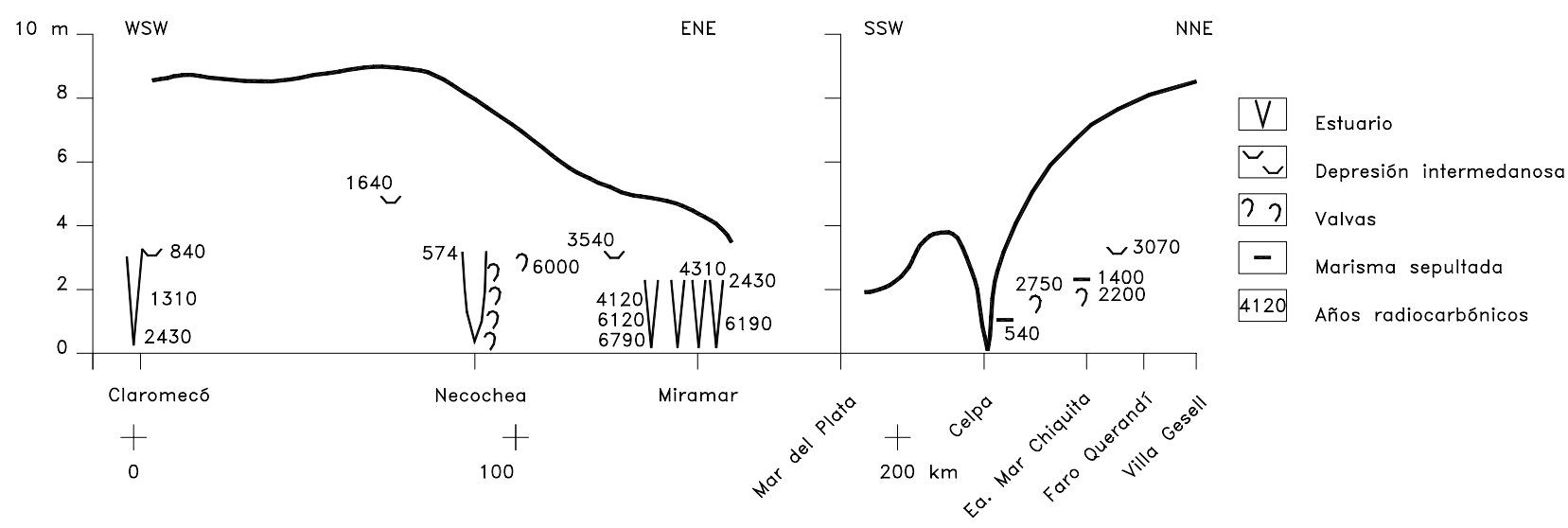

Figura 6. Perfil esquemático a lo largo de la costa con las edades y cotas de los sedimentos que fueron sepultados por médanos desde Claromecó hasta Villa Gesell.

Estos procesos alteraron el equilibrio sedimentario playa-médano litoral e indujeron problemas modernos de erosión costera (Isla, 1997; Isla y Tomazelli, 1999). Procesos posteriores de loteo y urbanización indujeron nuevos problemas de sobre- explotación y contaminación de acuíferos que están aumentando principalmente en los municipios de la Costa (González Arzac et al., 1992), Pinamar (González Arzac et al., 1994) y Villa Gesell.

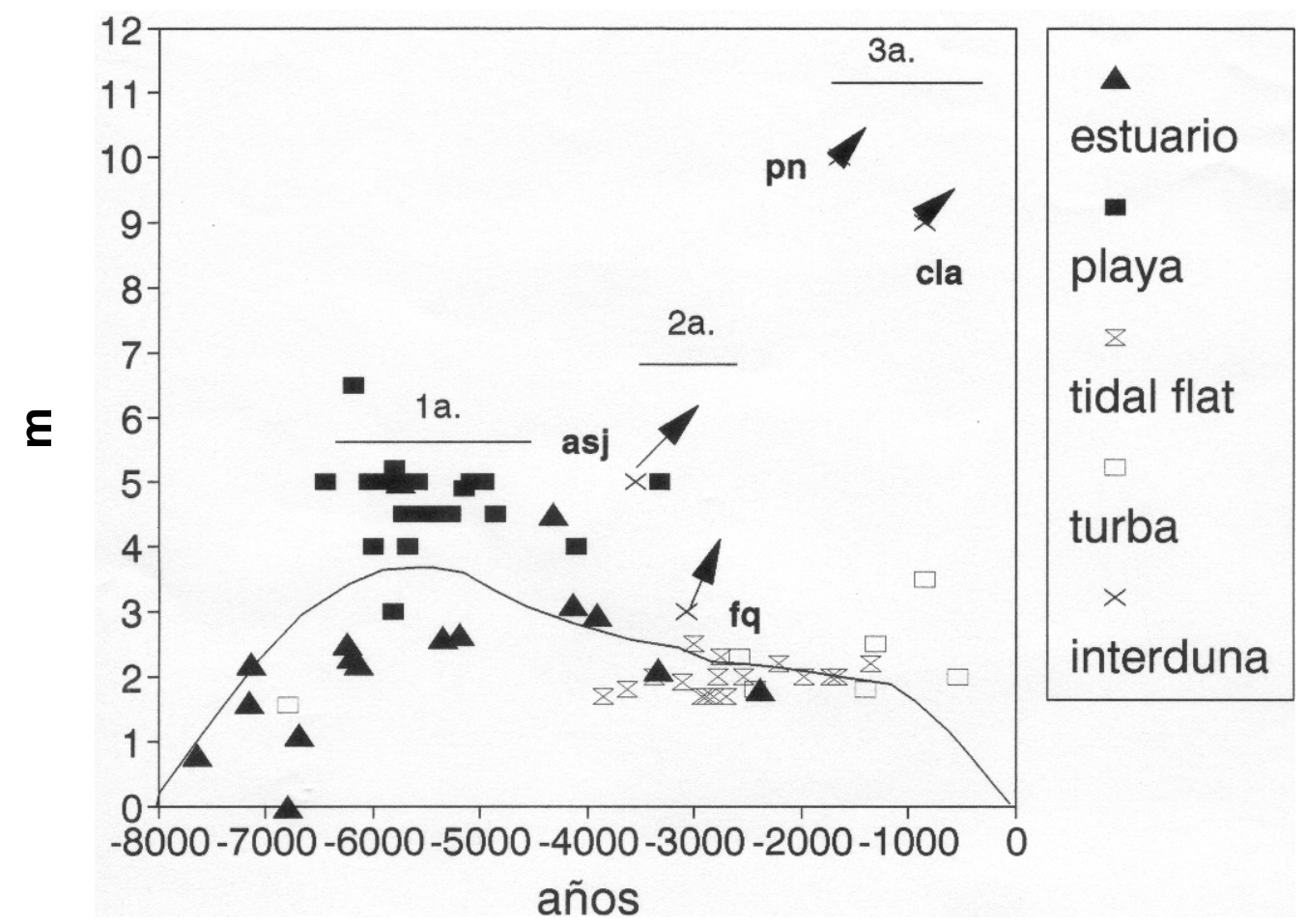

Figura 7. Dataciones de los sedimentos que infrayacen los médanos en ambas barreras, reconociendo la $1^{\mathrm{a}}$., $2^{\mathrm{a}}$. y $3^{\mathrm{a}}$. Generación de médanos litorales. De las dataciones de interduna: asj: Arenera San José; fq: Faro Querandí; pn: Punta Negra; cla: Claromecó. 


\section{Conclusiones}

A. El emplazamiento de médanos litorales en el Hemisferio Sur ha estado condicionado a la abundancia de arenas con relación al nivel máximo del mar ocurrido en el Holoceno medio. En Costa Bonita se ha constatado la presencia de playas de 6000 años que habrían permitido la formación de dunas litorales. B. Particularmente en el sudeste de la Provincia de Buenos Aires podemos identificarlos inmediatamente con posterioridad al momento en que estas barreras sepultaron acumulaciones de turba (marismas de agua dulce) que coronan las secuencias estuáricas (estuarios, lagunas costeras) y que corresponden al ciclo comprendido entre 6000 y 4000 años AP. La edad de esta instalación de los médanos en el tope de estuarios depende del ritmo de sedimentación y profundidad de estos ambientes.

C. Otros emplazamientos más modernos obedecen al sepultamiento de depresiones intermedanosas. Estas depresiones intermedanosas indican fehacientemente la presencia de dunas litorales durante la regresión del Holoceno superior, mientras la barrera oriental crecía de norte a sur (datación de 3070 \pm 40 años AP entre Faro Querandí y Ea. Mar Chiquita), o cuando la barrera austral se instalaba sobre el tope de acantilados (datación de 3540 \pm 60 años AP en la Arenera San José, Mar del Sur).

D. Posteriormente. hubo otros ciclos de movimiento de médanos que llevaron a la sepultación de depresiones intermedanosas en Punta Negra (Necochea) y de turbas en las cercanías de la boca de la laguna costera Mar Chiquita: Ea. Mar Chiquita (1400 \pm 60 años AP), arroyo Los Cueros (1340 \pm 50 años AP) y boca de Mar Chiquita (540 \pm 100 años AP).

E. La dinámica de la barreras está siendo significativamente alterada localmente con la fijación, forestación, urbanización y drenaje de los médanos que incrementaron los problemas de erosión costera, e iniciaron problemas de escasez o contaminación de aguas subterráneas.

\section{Agradecimientos}

Susana Serra ejecutó los análisis granulométricos. Marcelo Farenga realizó las figuras. Las dataciones radiocarbónicas fueron realizadas en el Laboratorio de Tritio y Radiocabono (LATYR, UNLP). Rodolfo Angulo realizó importantes sugerencias.

\section{Bibliografía}

Barreto, A. M. F.; Suguio, K.; Branco, F. C.; Almeida, T. I. R. (1997). As Megadunas Parabólicas Comostas do Quaternário Tardío do Médio Rio
São Francisco (Bahía) e suas Implicaçoes. Resumos expandidos, VI Congresso da Asociaçao Brasileira de Estudos do Quaternário e Reunião sobre o Quaternário da América do Sul. ABEQUA, Curitiba, Brasil, 27 de julio al 3 de agosto, 3-9.

Figini, A.J., Carbonari, J.E., Huarte, R.A. y Tonni, E. (1999). Cronología radiocarbónica del Holoceno de Punta Hermengo, Buenos Aires. XIV Congreso Geológico Argentino, Actas II, Salta, 63-66.

Folk, R. y Ward, W. (1957). Brazos River bar: a study in the significance of grain size parameters. Journal of Sedimentary Petrology 27, 1, 3-26.

Gomez Otero, J. (1994). Parada No. 1. Sitio Médanos del Riacho-Garganta del Delfín. En guía de campo de la VIIa. Reunión de campo del CADINQUA (Península Valdés y Centro - Noreste del Chubut). CenPat, P. Madryn, 52-55.

Gonzalez Arzac, R., Vizcaíno, A. y Campos Alfonso, F. (1992). Acuíferos costeros de la Provincia de Buenos Aires. Sector Punta Rasa-Punta Médanos. Parte I: Hidrogeología, hidrodinámica e hidráulica. Consejo Federal de Inversiones, Col. Hidrología subterránea $4,35 \mathrm{pp}$.

Gonzalez Arzac, R., Vizcaíno, A., Garay, R., Remorini, G., Perez Spina, R. y Campos Alfonso, F. (1992). Acuíferos costeros de alta vulnerabilidad. Consideración del factor hidrogeológico para el ordenamiento ambiental. Pinamar, Provincia de Buenos Aires, República Argentina. En Bocanegra, E. y Rapaccini, A. (eds.) Temas actuales de la hidrología subterránea, UNMDP-CFI, 397-409.

Illenberger, W.K. y Verhagen, B.Th. (1990). Environmental history and dating of coastal dunefields. Suid-Afrikaaanse Tydskrif vir Wetenskap 86, 311-314.

Isla, F. I. (1989). The Southern Hemisphere sea level fluctuation. Quaternary Sciences Review, 8, 359-368.

Isla, F. I. (1997). Procesos de canibalización de la barrera medanosa entre Faro Querandí y Mar Chiquita, Buenos Aires. Revista de la Asociación Geológica Argentina 52, 4, 539-548.

Isla, F. I. (1998). Holocene coastal evolution of Buenos Aires. Quaternary of South America \& Antarctic Peninsula, A. A. Balkema, 11, 297-321.

Isla, F.I., Bertola, G.R., Farenga, M.O., Serra, S.B. y Cortizo, L.C. (1998). Villa Gesell: un desequilibrio sedimentario inducido por fijaciones de médanos. Revista Asociación Argentina de Sedimentología $5,1,41-51$.

Isla, F.I., Cortizo. L.C. y Schnack, E.J. (1996). Pleistocene and Holocene beaches and estuaries along the Southern Barrier of Buenos Aires. Quaternary Science Reviews 15, 8-9, 833-841.

Isla, F.I. y Tomazelli, J. L. (1999). Eolian sand dispersals and modern erosion processes in Holocene coastal 
barriers: comparison between Mar Chiquita and Patos barriers (Argentina and Brazil). Revista Thalassas, 15, 2, 75-88

Isla, F.I., Schnack, E.J. y Weiler, N.E. (2000). Geological setting and Quaternary environments of Peninsula Valdés, Chubut, Argentina. Guidebook, Field Meeting IGCP 437, P.Madryn, October 2930, $34 \mathrm{pp}$.

Lanfredi, N.W., Pousa, J.L., Mazio, C.A. y Dragani, W.C. (1992). Wave-power potential along the coast of the Province of Buenos Aires, Argentina. Energy, 17, 11, 997-1006.

Muckersie, C. y Shepherd, M.J. (1995). Dune phases as time-transgressive phenomena, Manawatu, New Zealand. Quaternary International 26, 61-67.

Pye, K. y Bowman, G.M. (1984). The Holocene marine transgression as a forcing function in episodic dune activity on the Eastern Australia coast. En Thom, B.G. (de.) Coastal geomorphology in Australia, Academic Press, Australia, Ch. 9, 179-196.

Razigaeva, N., Korotky, A., Ganzey, L., Grebennikova, T., Mokhoba, L., y Bazarova, V. (1996). Coastal dunes in North-West Paficic Island areas. Proceedings of the Bahía Blanca International Coastal Symposium, Bahía Blanca, Universidad del Sur, 73-80.

Schnack, E. J., Fasano, J. L. e Isla, F. I. (1982). The evolution of Mar Chiquita lagoon, Province of Buenos Aires, Argentina. En Colquhoun, D. J. (ed.) Holocene Sea-Level Fluctuations: Magnitudes and Causes. IGCP 61, Univ. S. Carolina, Columbia, SC, 143-155.

Shulmeister, J. y Kirk, R.M. (1996). Holocene history and thermoluminescence based chronology of coastal dune ridges near Leithfield, Nort Canterbury, New Zealand. New Zealand Journal of Geology and Geophysics, 39, 25-32.

Stutz, S. (2000). Evolución comparada de las lagunas Mar Chiquita y Los Hinojales.(Pcia. de Buenos Aires): Reconstrucción de la historia de la vegetación durante el Holoceno. Tesis inédita. FCEN, UNMDP, 123 pp.

Turno Orellano, H. A. e Isla, F.I. (1999). Forestation of temperate coastal barriers as a sink of $\mathrm{CO}_{2}$ : a profitable business. Abstracts, $4^{\text {th }}$. LOICZ Open Science Meeting, Bahía Blanca, November 15-18, 93.

Violante, R.A. (1992). Ambientes sedimentarios asociados a un sistema de barrera litoral del Holoceno en la llanura costera al sur de Villa Gesell. Revista de la Asociación Geológica Argentina, 47, 2, 201-214. 